Dr. Morse spoke of the value of getting a record from the mother of the exact dietary of the child. I never treat a child without doing this, and I think it is exceedingly important. I secure not only a list of the various foods administered, but also a statement of the amounts of each food.

The examination of the stools, as has been suggested by Dr. Talbot, is not a difficult procedure, and one can gather much valuable information from the macroscopic study alone. The microscopic examination is importunt, but not so much so as the macroscopic. The sooner we realize that the examination of the stools is an easy procedure, the sooner we shall employ it as a routine measure.

\section{NITROUS OXID AND OXYGEN ANESTHESIA *}

WILLIAM D. HAGGARD, M.D. NASIIVILLE, T'ENN.

The advances in the use and perfection of nitrous oxid anesthesia since the report of the Anesthesia Commission on this subject, at the meeting of 1908 , seem to consist of the following:

1. The emplayment of this agent, with modifications, ás the routine anesthetic in several of the large clinies of this country.

2. The demonstration clinically and experimentally of the advantages of nitrogen oxid and oxygen over ether, in the prevention of shock, the conservation of immunity and its value in the case of the handicapped patient (Crile).

3. The establishment of rebreathing of nitrous oxid and oxygen for two or three minute periods, as harmless and beneficial, with the great reduction in cost of this anesthetic (Gatch).

It has already been shown that nitrous oxid is the safeet of all anesthetics and the most pleasant to take; that it requires the shortest time for induction; that there is almost immediate recovery after its discontinuance, and that it has no bad after-effects. There is no stage of excitement, and excitement is absent when the patient returns to consciousness. Dentists, who have used it in short administrations for many years, state that literally millions of administrations have yielded an infinitesimal number of deaths.

It is not absolutely free from danger, however. Death can occur from its continuous administration, without admission of air or oxygen in from two to four minutes. In overdosage, death is caused by asphyxiation and cardiac inhibition. In the fatal animal experiments, sudden arrest of the heart in overdistention was observed. The danger-signals with this anesthetic are:

1. Deep and persistent cyanosis.

2. Depression and slowing of the pulse.

3. Vomiting.

Cyanosis is the first indication of trouble, and gives startling warning of impending danger. Discontinuance of gas and giving of oxygen, which should be always at hand, uniformly and promptly dissipate all danger.

Crile has shown in the physiologic laboratory that animals under nitrous oxid withstand shock-producing trauma much better than under ether. The resistance of animals rendered pathologic from infections, hemor.. rhage, and liyperthyroidism, likewise, was strikingly better under nitrous oxid than under ether. These laboratory observations were corroborated by the histologic examination of the prinitive ganglion cells of the central nervous system.

* Approved by the Committce on Anesthesia of the American Medical Assoclation.
Crile's recent investigations in cytolysis show that there is decidedly more destruction of chromatin after ether than after zitrous oxirl. Again, fluere is no lowering of the phagocytic power alter nitrous oxid, as after ether. Nitrous oxid does not reduce hemoglobin or anuse any permanent blood change. 'There is no acetone or indicanuria as a result. P'ostanesthetic conplications arc alssent.

Although oxygen was used by Andrews with nitrous oxid as early as 1868, some of the later apparatus provided for the admixture of air. Beran employs this gas and air mixture with success, and 1 have used it in a series of over 100 cases. 'Whis mixture, however, dloes not provide such smootl anesthesia as does the mixture with oxygen. On account of the large atmospheric eontent of nitrogen, if enough air is used to do gway with cyanosis entirely, it so dilutes the mixture that complete anesthesia is interfered with. While cyanosis is not desirable and can be prevented by the addition of oxygen, yet it should be understood that the cyanosis is not neurly so dangerons as that cyanosis produced by ether or chloroform-a cyanosis duc to cardine and respiratory depression.

It seems to have been established by Gatch that rebreathing nitrous oxid and oxygen in periods of two mimutes is not only perfectly safe, but helpful to respiration, circulation and blood-pressirc. Moreover, rebreathing reduces the expense greatly, which was partly responsible for the somewhat restricted use of this agent. Rebreathing seems to be more satisfactory than the continuous administration of the gas. 'The respirations are deeper and fuller, and the pulse is slowed by the therapentic excess of carbon dioxid stimulating the center of cardio-inhibition. The tempernture is slightly raisorl. The argument for rebreathing is that carbon dioxid under 4 per cent. concentration is non-toxic; that in normal and somewhat increased amounts in the blood it is the normal stimulus to the venous wall; that the aholition of venous tonus and not arterial is the primary cause of failure of circulation in shock. Carbon dioxid stimulates the cardio-inhibitory, vasomotor and respiratory centers, and an increase such as is afforded by rebreathing during gas and oxygen raises the bloodpressure and is thus an casily available preventive of slock. The loss of body heat by expirerl air is conserved by rebreathing and artificial warming of the gases is rendered unnecesary.

The apparatus of Gateh provirling for rebrenthing is extremely simple, portable and inexpensive. It has a rublier sleeve that fits snugly and conveniently over the face-piece, preventing lealiage of gases and the ingress of air which checks the anesthesia. The patient can be given air or gas, with or without oxygen, and madr? to breathe the mixed gases to and from the bag. Wren a little air allowed to mix the gases spoils the anesthesia. The apparatus has an atlachment permitting ether to be added when needed for short periods, all without removal of the mask, until the anesthesia is to be permanently withdrawn. It is a very powerful etherizing device when necded.

It is not necessary to attempt to give any arbitrary percentage of oxygen. Just enough to dispel the cyanosis is the aim and, roughly speaking, a pulf of oxygen in each bag of nitrous oxid that is to he rebreathed is suftficient. Keep the paticut pink, is the rule. If the color cannot be kept good, it is better to give ether by the open method. 
Not all patients, notably not the very robust and alcololies, can be sufficiently relaxed without disagreeable ryanosis. In these, ether given for three or four minlites in the mask or by the open method, will usually ace(omplish relaxution and oblivion. The quantity of ether is negligible. When rigidity is overcome the gas may be resumed. A little ether, co small in quantity that the patient is never aware of it, is given in about threefouths of the aldominal cases at Jolnns Hopkins Hospital (Gatch). The post-operative discomfort is less with a little ether and no cyanosis than with no ether and prolonged cyanosis. Pronounced cyanosis is apt to be followed by lieadache.

'T'ter estimates that a small quantity of ether given in this way will be necessary in about 10 per cent. of the cases. In laparotomies three, five or seven minutes of ether' will be required in about 40 per cent. of cases.

Gas and oxygen can be used with impunity where ether is contraindicated, i. e., in kidney disease. Nitrous oxid has also been employed in advanced pulmonary lesions and seems to have caused no mortality. It is particularly helpful in those desperate cases from any anuse that urgently demand operation and yet are so risky that the surgeon realizes that ether or chloroform is the added weight which depresses the beam.

'The borderline cases in which the operator seriously questions the wisdom of trying to do anything, may have surgica! aid extended safely, so far as the anesthetic is roncerned, by nitrous oxid and oxygen, but only at the greatest hazard with ether or chloroform. Moreover, the inevitable, though small, anesthetic mortality from pneumonia, anuria, f'atty degeneration of the liver, etc., can be be prevented.

'The chief' class of cases rendering nitrous oxid unsafe is that of heart lesions, whether myocardial or valvular.

Anesthetization with nitrous oxid is incontestably more difficult than ether. It requires special training and expertness to acquire the technic. Crile has had it administered practically as his routine anesthetic in over 1,000 ('ases. 'Therc has been one death six hours afterward which he charges to the ancsthetic. With the increased experience acquired by his special anesthetist he feels that this fatality could now be averted.

The danger, therefore, is not so much in the agent as in the administrator, but this is equally true of the other anesthetics. The simple cases should he chosen first.

It is therefore not adaptable for the all-round use of the general practitioner, but will grow greatly in popularity in the lighlly perfected clinies, in hospitals with expert permunent anesthetists, and with those who specialize in anestheties. Fortunately most of the major surgery and graver traumas are cared for under these conditions, and thus the desperate-chance patient may have this added safeguard and adjuvant to life-saving.

(ias and oxygen are not only indicated where the risk is great, but routinely they are a special boon to patients Who have been operated on before and who have a more or less justifiable and vigorously expressed dread of the primary "smothering" effects of ether, and the secondary reeling of mal de mer.

Nitrous oxid (an be safely administered for two or three hours, and at Johns Hopkins Hospital where it las been used routinely on the surgical side in over 1,000 (ases, Gatch kept one patient under its influence for five hour's without ill effects. It can be given longer with safety than any other anesthetic.

A preliminary dose of mor'phin gr. $1 / 4$ and atropin gr. 1,150 or half tian anount is useful in the majority of cases to assuage the fear of the anesthetic and of the operative ordeal. Anesthesia is induced more easily and proreeds more tranquilly: a smaller quantity is recuired and the after pain is anmulled. No lood or drink should be given for at least four hours prior to operation. Do not begin the operation too soon.

('rile gives $1 / 150 \mathrm{gr}$. scopolamin or less two hours: before operation. It induces the "twilight slumber" and obliterates any fright or even anxicty about the operation. The effect, and with the preliminaly lose of morphin followed by the anesthetic lulls the patient jnto a drowsy somnolence which deprives the entire day of painlul recollection.

Nitrous oxid and oxygen anesthesia with the apparatus not permitting rebreathing, costs about $\$ 5.00$ an hour. W'ith the apparatus of Gatch, obtaining the other benelits of rebreathing, the cost is reduced to $\$ 1.00$ or $\$ 1.50 \mathrm{an}$ hour. 'This cost may be further greatly reduced by installing, for a few himdred dollars, a permanent plant in the basement of the hospital, for the manufacture of nitrous oxid. It can be piped to the operating-room, thus doing away with the noise male by the escape of the gas under pressure in the cylinders.

Continuous auscultation of the heart by a phonendoscope, as practiced by Cushing and advised by Teter, gives accurate information, and allows both hands of the anesthetist to be employed with the patient and the appiaratus.

\section{ANESTHESIA IN 'TRAUMA'TIC SURGERY*}

$$
\begin{aligned}
& \text { GASTON 'TORRANCL, M.D. } \\
& \text { BIRM NOHAM, NIA. }
\end{aligned}
$$

On being asked by the committee to report on anesthesia in traumatic surgery from the Birmingham district, I sent a circular letter to a number of surgeons in this country and abroad, asking them to give their experience and observations in regard to this subject; and below will be found a coniensed form of the reports submitted by them.

Professor Fisclsberg writes that in the Vienna clini: they have a special station devoted to traumatic surgical cases. He advises that as small an amount of tie anesthetic be used as possible. No morphin or scopolamin should be used in fractures of the skull as there is danger of sudden collapse. Morphin should precerte: the anesthetic in fractured ribs, thereby aroiding dyspnea. Ile prefers using Billroth's mixture (chloroform. ether and alcohol) followed by ether where a general anesthetic is to be used. Spinal anesthesia is to be used only where others are contra-indicated. He has never observed a death from the anesthetic. The greatest precantions are to be taken where a general anesthetic is used as traumatized patients are much more sensitive to the effects of anestheties than other. Where possible the operation should be postponed until the first period of shock has been passed.

1)r. (Charles H. Mayo says that he and his colleagues have practically no trammatic casss in their surgery and that they have had very little opportunity to observe the effects of anesthesia in this cluss of work.

1)r. George W. Crile writes as follows:

Wherever possible, nitrous oxid oxygen anesthesia is used. I base my preference on the observation that under nitrous oxid anesthesia there is less shock than under ether. That is,

* Approved by the Committee on Anesthesin of the Amerlenn Medical Associlition. 